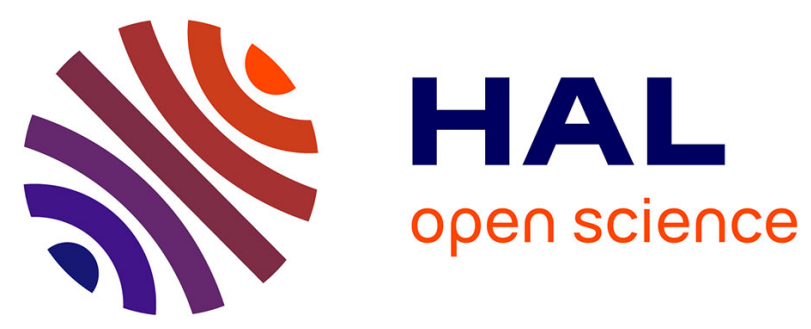

\title{
Kinetics of metal extraction in ionic liquids: Eu3+/HNO3//TODGA/[C1C4im] $[$ Tf2N] as a case study
}

Michal Sypula, Ali Ouadi, Clotilde Gaillard, Isabelle Billard

\section{To cite this version:}

Michal Sypula, Ali Ouadi, Clotilde Gaillard, Isabelle Billard. Kinetics of metal extraction in ionic liquids: Eu3+/HNO3//TODGA/[C1C4im][Tf2N] as a case study. RSC Advances, 2013, 3 (27), pp.10736. 10.1039/c3ra40651b . hal-02271589

\section{HAL Id: hal-02271589 \\ https://hal.science/hal-02271589}

Submitted on 27 Aug 2019

HAL is a multi-disciplinary open access archive for the deposit and dissemination of scientific research documents, whether they are published or not. The documents may come from teaching and research institutions in France or abroad, or from public or private research centers.
L'archive ouverte pluridisciplinaire HAL, est destinée au dépôt et à la diffusion de documents scientifiques de niveau recherche, publiés ou non, émanant des établissements d'enseignement et de recherche français ou étrangers, des laboratoires publics ou privés. 
Cite this: RSC Advances, 2013, 3, 10736

Received 6th February 2013, Accepted 15th April 2013

DOI: $10.1039 / c 3 r a 40651 b$

www.rsc.org/advances

\section{Kinetics of metal extraction in ionic liquids: $\mathrm{Eu}^{3+} /$ $\mathrm{HNO}_{3} / / T O D G A /\left[\mathrm{C}_{1} \mathrm{C}_{4} \mathrm{im}\right]\left[\mathrm{Tf}_{2} \mathrm{~N}\right]$ as a case study}

\author{
Michal Sypula, ${ }^{\text {a }}$ Ali Ouadi, ${ }^{\text {a }}$ Clotilde Gaillard ${ }^{\mathrm{b}}$ and Isabelle Billard*a \\ The kinetics of metal transfer in the system $\mathrm{Eu}^{3+} / \mathrm{HNO}_{3} / / \mathrm{TODGA}_{/}\left[\mathrm{C}_{1} \mathrm{C}_{4} \mathrm{im}\right]\left[\mathrm{Tf}_{2} \mathrm{~N}\right]$, where TODGA is \\ $N, N, N^{\prime}, N^{\prime}$-tetraoctyl diglycolamide, is shown to depend on the chemical conditions (nitric acid and TODGA \\ concentrations) and the time needed to reach equilibrium which may vary from less than 10 min to more \\ than $4 \mathrm{~h}$. At $\left[\mathrm{HNO}_{3}\right]=4 \mathrm{M}$, a detailed kinetic study is performed for two different concentrations of \\ TODGA. It is shown that the time required for water and acid solubilisation in the IL phase is very short, as \\ is the time for IL solubilisation in the aqueous phase. By contrast, the extraction of Eu(III) takes more than \\ $100 \mathrm{~min}$ to be completed and depends on the TODGA concentration. On the basis of these experimental \\ facts, a simple kinetic model is proposed which is able to account for the data.
}

\section{Introduction}

Solvent extraction is presently one of the most developed separation techniques. The versatility of solvent composition and extraction conditions together with easy implementation at an industrial scale as a continuous process make it one of the main separation techniques even in such a demanding field as nuclear waste recycling. However, commonly used molecular solvents are usually highly volatile with significantly low flash-points. Moreover, in the nuclear field, their radiolysis products often cause undesirable changes in the extraction properties or selectivity of the system.

A possible solution to those problems could be the use of ionic liquids (ILS) which have recently gained much attention as a new class of solvents. ${ }^{1-3}$ However, despite many very interesting properties, such as non-volatility, ${ }^{4}$ non-flammability, ${ }^{4}$ radiolysis resistance, ${ }^{5}$ and incredibly high extraction efficiencies in many cases ${ }^{6-8}$ ILs may also present disadvantages that should be carefully addressed. Various authors have highlighted the difference in extraction mechanisms between ILs and molecular solvents ${ }^{6,9-11}$ that leads to undesirable pollution of the aqueous phase by the costly ILs' anions and/or cations. Surprisingly enough, few papers pinpoint the possible problems arising from the rather high viscosity of ILs $^{12,13}$ putting the emphasis on technical considerations in connection with ILs use at an industrial scale. A few authors evidenced slow kinetics of metal transfer by use of ILs ( $c a$. 120 min to reach equilibrium for $\operatorname{Ln}(\mathrm{III})$ extraction in Yoon et al.,$^{14}$ or for Am(III) extraction in Sengupta et $a l .{ }^{15}$ ) but they

${ }^{a} I P H C, C N R S / I N 2 P 3$ and Université de Strasbourg, 23 rue du Loess, 67037 Strasbourg Cedex 2, France. E-mail: isabelle.billard@iphc.cnrs.fr

${ }^{b}$ IPN-Lyon, UMR 5822, 4 rue Enrico Fermi, 69622 Villeurbanne Cedex, France hardly mention it as a possible problem and to the best of our knowledge, only a single publication touches on the subject. ${ }^{16}$

Therefore, in this paper, we investigate some aspects of metal transfer kinetics in an extraction biphasic system where the traditional molecular solvent has been replaced by an ionic liquid, namely 1-methyl-3-butyl-imidazolium bis(trifluoromethanesulfonyl)imide (hereafter noted as $\left[\mathrm{C}_{1} \mathrm{C}_{4} \mathrm{im}\right]\left[\mathrm{Tf}_{2} \mathrm{~N}\right]$, where $\mathrm{Tf}_{2} \mathrm{~N}^{-}$stands for the $\left(\mathrm{CF}_{3} \mathrm{SO}_{2}\right)_{2} \mathrm{~N}^{-}$anion). As the extracting agent, we chose $N, N, N^{\prime}, N^{\prime}$-tetraoctyl diglycolamide (TODGA, see Scheme 1), first synthesized with five other diglycolamides in 2001 by Sasaki et al. ${ }^{17}$ and which proved to have a very high extraction affinity towards trivalent lanthanide and actinide ions from highly concentrated nitric acid solutions towards dodecane. As this promising extractant was recently employed by French researchers in the so-called Innovative SANEX process (Separation of Actinides by Extraction) in which An(III) was co-extracted with $\mathrm{Ln}(\mathrm{III})^{18}$ we chose europium as the extracted metallic entity in this study.

We studied the extraction kinetics of $\mathrm{Eu}$ (III) towards $\left[\mathrm{C}_{1} \mathrm{C}_{4} \mathrm{im}\right]\left[\mathrm{Tf}_{2} \mathrm{~N}\right]$ using TODGA for various nitric acid concentrations of the aqueous phase. The time needed to reach equilibrium appears to be highly dependent on the chemical conditions. We propose a general chemical model based on simple kinetic considerations which we show to quantitatively recover the experimental variations.

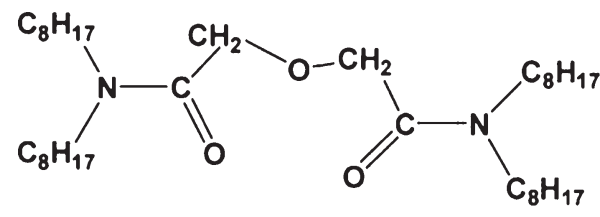

Scheme 1 Chemical structure of TODGA. 


\section{Experimental}

\subsection{Chemicals}

1-Butyl-3-imidazolium bis(trifluoromethanesulfonyl)imide $\left(\left[\mathrm{C}_{1} \mathrm{C}_{4} \mathrm{im}\right]\left[\mathrm{Tf}_{2} \mathrm{~N}\right]\right)$ was purchased from Solvionic, Verniolle, France (purity: 99.5\%) and dried in vacuum at a raised temperature of $60 \pm 1{ }^{\circ} \mathrm{C}$ prior to use, according to a previously published procedure. ${ }^{19}$ Europium nitrate hexahydrate was obtained from Riedel-de Haen and $\mathrm{HNO}_{3}$ was from

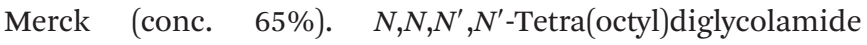
(TODGA, see Scheme 1) of purity $>97 \%$ was obtained from Betulinines, Czech Republic, and used without further purification. Comparative extraction experiments with purified TODGA ( $>99.9 \%$ purity) synthesized at and provided by Forschungszentrum Jülich, Germany ${ }^{20,21}$ showed no difference between the two providers. All samples were prepared with ultra-pure water (Millipore).

\subsection{Extraction procedures and measurements}

The organic phase consisted of $1 \mathrm{mM}$ or $2 \mathrm{mM}$ of TODGA (weighted amount) dissolved in $\left[\mathrm{C}_{1} \mathrm{C}_{4} \mathrm{im}\right]\left[\mathrm{Tf}_{2} \mathrm{~N}\right]$ and dried in vacuum at $60 \pm 1{ }^{\circ} \mathrm{C}$ prior to use. $0.5 \mathrm{~mL}$ of the organic phase was brought into contact with $0.5 \mathrm{~mL}$ of an aqueous phase of variable nitric acid concentration containing $\mathrm{Eu}^{3+}$ in a concentration of $10 \mu \mathrm{M}$. Both phases were brought into contact in a mechanical shaker at room temperature $(20 \pm 1$ $\left.{ }^{\circ} \mathrm{C}\right)$ for variable length of time followed by 2 min centrifugation. The "mixing time" hereafter used in the text corresponds to the time during which the samples were shaken, from $5 \mathrm{~min}$ to $25 \mathrm{~h}$, without taking into account the contact time during preparation of the sample series, during transport from the shaker to the centrifuge, during centrifugation or before complete separation of the two phases. These additional contact times were reduced to the minimum possible but could not be reduced to less than 6 min (including the centrifugation time). Therefore, as in usual extraction procedures, note we did not perform any pre-equilibration of the aqueous and IL phases.

The aqueous phase was sampled $(100 \mu \mathrm{L})$ and diluted prior to Eu concentration determination using ICP-MS (Agilent 7500i). The data are first expressed as the remaining total europium concentration in the aqueous phase, as obtained by the ICP-MS measurements, but the extraction of $\mathrm{Eu}$ is also expressed by the distribution ratio, $D_{\mathrm{Eu}}$, calculated according to:

$$
D_{\mathrm{Eu}}=\frac{[\mathrm{Eu}]_{\mathrm{aq}, \text { ini }}-[\mathrm{Eu}]_{\mathrm{aq},(t)}}{[\mathrm{Eu}]_{\mathrm{aq},(t)}}
$$

The proton concentration in the aqueous phase was determined by titration using a titration set up from Schott (Ttitrinorm, Titroline Easy, uncertainty on values within 5\%). Water content in the organic phase was determined using the Karl-Fischer technique (Mettler-Toledo, 10\% uncertainty).

The concentration of $\mathrm{C}_{1} \mathrm{C}_{4} \mathrm{im}^{+}$in the aqueous phase was measured using ${ }^{1} \mathrm{H}$ NMR (Bruker, 300MHz) by mixing an appropriate volume of the sample with $100 \mu \mathrm{L}$ of an internal standard consisting of $50 \mathrm{mM} \mathrm{CH} \mathrm{CH}_{3} \mathrm{COONa}$ in $\mathrm{D}_{2} \mathrm{O}$. The concentration of $\mathrm{C}_{1} \mathrm{C}_{4} \mathrm{im}^{+}$was obtained from the area ratio of the ${ }^{1} \mathrm{H}$ NMR signal of $\mathrm{C}_{1} \mathrm{C}_{4} \mathrm{im}^{+}$to the $-\mathrm{CH}_{3}$ peak of sodium acetate $\left(\delta_{\mathrm{H}}=2.08 \mathrm{ppm} ; \mathrm{D}_{2} \mathrm{O}, 1.7 \%\right.$ uncertainty).

\subsection{Fitting procedures}

The obtained experimental ICP-MS data on the total $\mathrm{Eu}^{3+}$ aqueous concentration as a function of the mixing time were fitted to a model (least square adjustment) by use of dedicated Fortran routines with the help of the CERN libraries. In the minimization procedure, all data points were given the same weight.

\section{Experimental results}

\subsection{Kinetics of $\mathrm{H}_{2} \mathrm{O}, \mathrm{H}_{3} \mathrm{O}^{+}$and $\mathrm{C}_{1} \mathrm{C}_{4} \mathrm{im}^{+}$}

The kinetics of $\mathrm{H}_{2} \mathrm{O}$ solubilisation in the IL phase in the presence of $\mathrm{Eu}^{3+}$ was determined as a function of the mixing time, for various chemical conditions:

i) $\left[\mathrm{HNO}_{3}\right]=1 \mathrm{M},[\mathrm{TODGA}]=0 \mathrm{M}$.

ii) $\left[\mathrm{HNO}_{3}\right]=1 \mathrm{M},[\mathrm{TODGA}]=1 \mathrm{mM}$.

iii) $\left[\mathrm{HNO}_{3}\right]=4 \mathrm{M},[\mathrm{TODGA}]=1 \mathrm{mM}$.

iv) $\left[\mathrm{HNO}_{3}\right]=7 \mathrm{M},[\mathrm{TODGA}]=1 \mathrm{mM}$.

The results are displayed in Fig. 1. Note that values obtained for case iii) at $t=1500 \mathrm{~min}$ (not plotted on the graph) are perfectly in line with the average value plotted in Fig. 1.

In a second step, the concentration of $\mathrm{H}_{3} \mathrm{O}^{+}$in the aqueous phase was measured under the following chemical conditions as a function of the mixing time:

i) $\left[\mathrm{HNO}_{3}\right]=1 \mathrm{M}$, $[$ TODGA $]=1 \mathrm{mM}$.

ii) $\left[\mathrm{HNO}_{3}\right]=4 \mathrm{M},[\mathrm{TODGA}]=1 \mathrm{mM}$.

iii) $\left[\mathrm{HNO}_{3}\right]=4 \mathrm{M}$, $[\mathrm{TODGA}]=2 \mathrm{mM}$.

iv) $\left[\mathrm{HNO}_{3}\right]=7 \mathrm{M},[\mathrm{TODGA}]=1 \mathrm{mM}$.

The results are presented in Fig. 2. Again, values obtained for case ii) at $t=1500 \mathrm{~min}$ and iii) at $t=1508 \mathrm{~min}$ are perfectly in line with the average values plotted in Fig. 2 .

In addition, for a fixed mixing time of $180 \mathrm{~min}$, the $\mathrm{H}^{+}$ concentration was measured as a function of the initial acid concentration. The data are reported in Fig. 3, together with

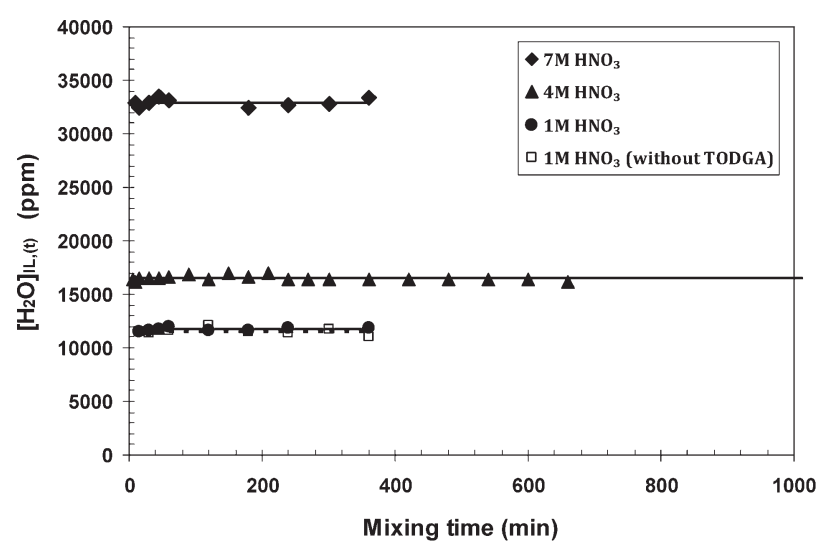

Fig. 1 Solubility of water in the IL phase as a function of the mixing time for 1, 4 and $7 \mathrm{M} \mathrm{HNO}_{3}$. Solid lines represent the average values. Org. phase: $1 \mathrm{mM}$ TODGA in $\left[\mathrm{C}_{1} \mathrm{C}_{4} \mathrm{im}\right]\left[\mathrm{Tf}_{2} \mathrm{~N}\right]$. Aq. phase: $10 \mu \mathrm{M} \mathrm{Eu}\left(\mathrm{NO}_{3}\right)_{3}, 1,4$ or $7 \mathrm{M} \mathrm{HNO}_{3}$. 


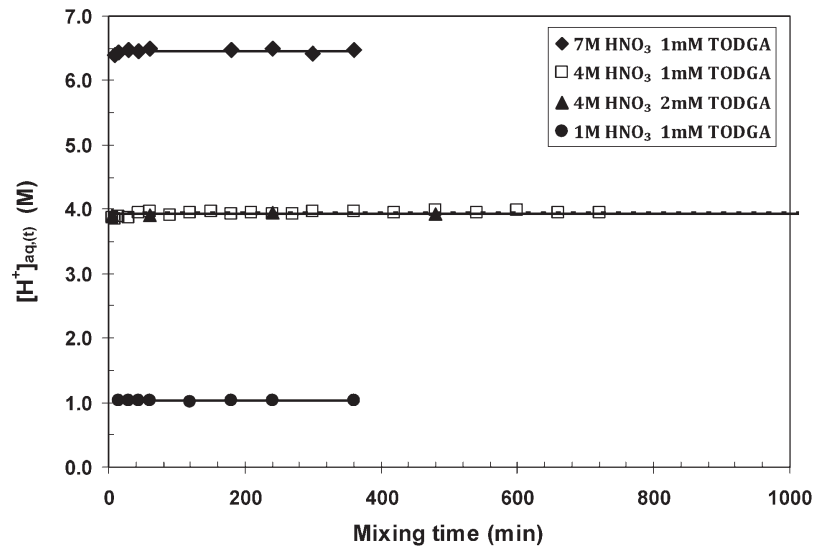

Fig. 2 Concentration of $\mathrm{H}_{3} \mathrm{O}^{+}$in the aqueous phase as a function of the mixing time for 1, 4 and $7 \mathrm{M} \mathrm{HNO}_{3}$. Solid lines represent the average values. Org. phase: 1 or $2 \mathrm{mM}$ TODGA in $\left[\mathrm{C}_{1} \mathrm{C}_{4} \mathrm{im}\right]\left[\mathrm{Tf}_{2} \mathrm{~N}\right]$. Aq. phase: $10 \mu \mathrm{M} \mathrm{Eu}\left(\mathrm{NO}_{3}\right)_{3}, 1,4$ or $7 \mathrm{M}$ $\mathrm{HNO}_{3}$.

the average value obtained from the data in Fig. 2. For comparison, the $\mathrm{H}^{+}$solubility in $\left[\mathrm{C}_{1} \mathrm{C}_{4} \mathrm{im}\right]\left[\mathrm{Tf}_{2} \mathrm{~N}\right]$ without TODGA, reported by Bonnaffe-Moity et al., ${ }^{22}$ is shown in the Fig. 3.

Finally, the kinetics of $\mathrm{C}_{1} \mathrm{C}_{4} \mathrm{im}^{+}$solubility in the aqueous phase was determined as a function of the mixing time for the following conditions:

i) $\left[\mathrm{HNO}_{3}\right]=1 \mathrm{M},[\mathrm{TODGA}]=1 \mathrm{mM}$.

ii) $\left[\mathrm{HNO}_{3}\right]=7 \mathrm{M},[\mathrm{TODGA}]=1 \mathrm{mM}$.

The results are presented in Fig. 4.

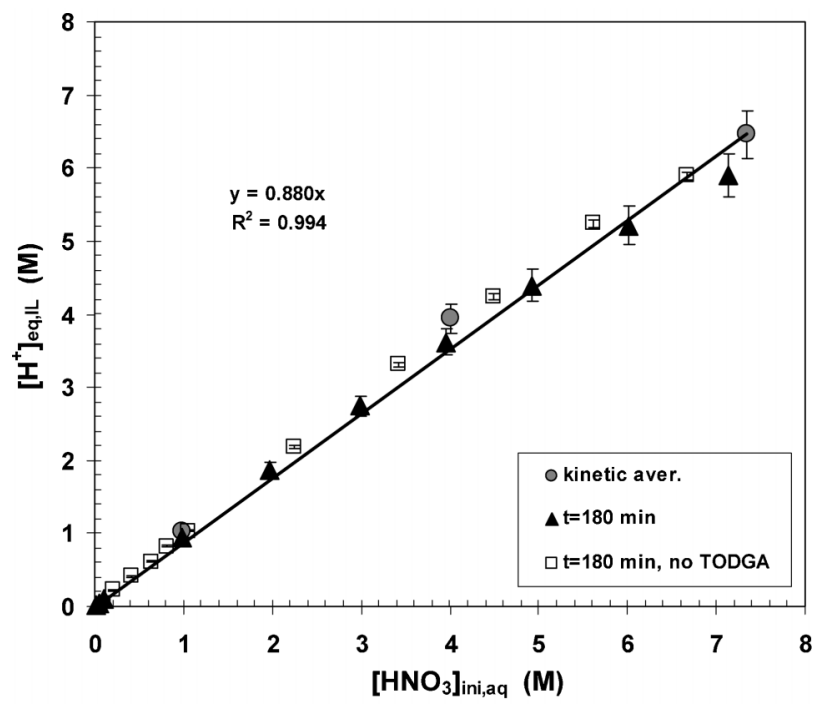

Fig. $3\left[\mathrm{H}^{+}\right]_{\text {eq, IL }}$ as a function of $\left[\mathrm{HNO}_{3}\right]_{\text {ini,aq. }}$. Closed triangles: fixed mixing time $t$ $=180 \mathrm{~min}$. Closed circles: average from the kinetics study (see Fig. 2). Open squares: fixed mixing time $t=180 \mathrm{~min}$ but without TODGA. Solid line: linear fit of the data (only for experiments with TODGA). Org. phase: $1 \mathrm{mM}$ TODGA in $\left[\mathrm{C}_{1} \mathrm{C}_{4} \mathrm{im}\right]\left[\mathrm{Tf} \mathrm{f}_{2} \mathrm{~N}\right]$. Aq. phase: $10 \mu \mathrm{M} \mathrm{Eu}\left(\mathrm{NO}_{3}\right)_{3}$, variable initial $\mathrm{HNO}_{3}$.

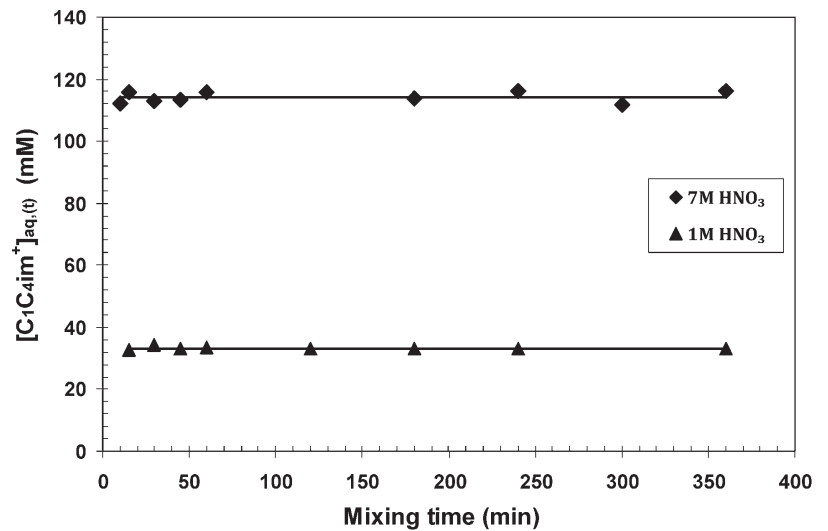

Fig. 4 Concentration of $\mathrm{C}_{1} \mathrm{C}_{4} \mathrm{im}^{+}$in the aqueous phase as a function of the mixing time for 1 and $7 \mathrm{M} \mathrm{HNO}_{3}$. Solid lines represent the average values. Org. phase: $1 \mathrm{mM}$ TODGA in $\left[\mathrm{C}_{1} \mathrm{C}_{4} \mathrm{im}\right]\left[\mathrm{Tf}_{2} \mathrm{~N}\right]$. Aq. phase: $10 \mu \mathrm{M} \mathrm{Eu}\left(\mathrm{NO}_{3}\right)_{3}, 1$ or $7 \mathrm{M}$ $\mathrm{HNO}_{3}$.

\subsection{Extraction kinetics of Eu from variable concentration of $\mathrm{HNO}_{3}$}

Preliminary experiments in the absence of TODGA, for $1 \mathrm{M}$ nitric acid concentration, showed no europium extraction, in the time mixing range 15-360 $\mathrm{min}$. This is in line with other studies, showing no significant Eu extraction without TODGA in $\left[\mathrm{C}_{1} \mathrm{C}_{2} \mathrm{im}\right]\left[\mathrm{Tf}_{2} \mathrm{~N}\right],{ }^{6}$ or no Am(III) extraction without TODGA in $\left[\mathrm{C}_{1} \mathrm{C}_{n} \mathrm{im}\right]\left[\mathrm{Tf}_{2} \mathrm{~N}\right](n=4,6,8) .{ }^{15}$ Therefore, the extraction data presented below are solely due to the presence of TODGA in the IL phase.

The europium distribution ratio has been measured as a function of mixing time (up to $6 \mathrm{~h}$ ) for various initial values of the nitric acid concentration, with TODGA concentration equal to $1 \mathrm{mM}$. The results are shown in Fig. 5. In addition, the extraction of the metal from $10 \mathrm{mM} \mathrm{HNO}_{3}$ was performed but already after $5 \mathrm{~min}$, precise determination of $D_{\mathrm{Eu}}$ was not possible due to the metal concentration in the aqueous phase

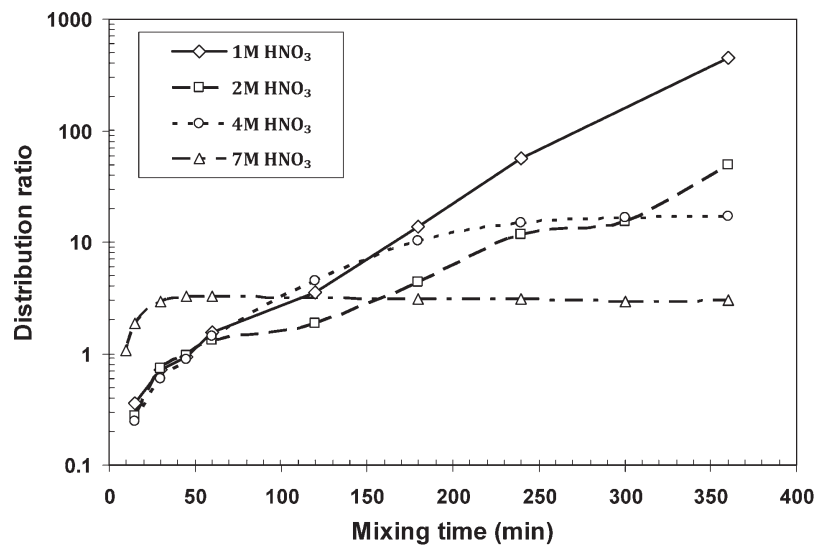

Fig. 5 Extraction of europium as a function of mixing time for variable concentrations of nitric acid. Solid lines are guides for the eye only. Org. phase: 1 mM TODGA in $\left[C_{1} C_{4} \mathrm{im}\right]\left[\mathrm{Tf}_{2} \mathrm{~N}\right]$. Aq. phase: $10 \mu \mathrm{M} \mathrm{Eu}\left(\mathrm{NO}_{3}\right)_{3}$, variable $\mathrm{HNO}_{3}$ concentration. 


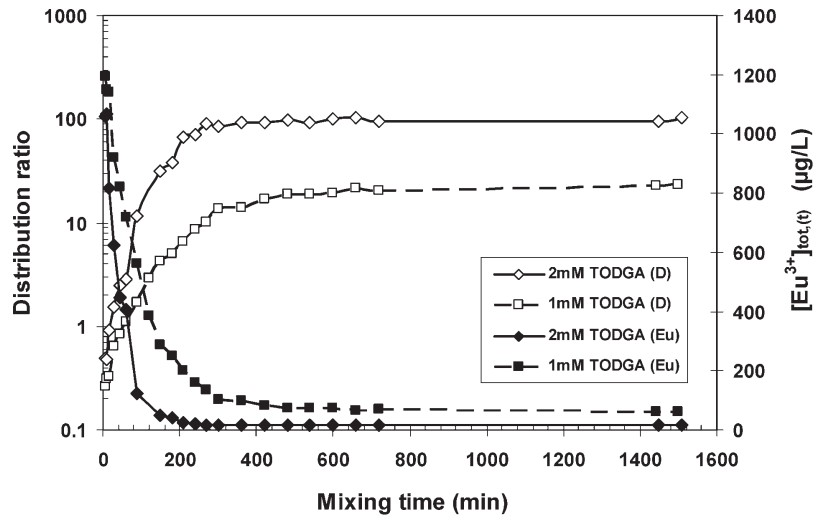

Fig. 6 Distribution ratio and aqueous phase concentration of europium as a function of mixing time. Lines are guides for the eye only. Org. phase: 1 or $2 \mathrm{mM}$ TODGA in $\left[\mathrm{C}_{1} \mathrm{C}_{4} \mathrm{im}\right]\left[\mathrm{Tf}_{2} \mathrm{~N}\right]$. Aq. phase: $10 \mu \mathrm{M} \mathrm{Eu}\left(\mathrm{NO}_{3}\right)_{3}, 4 \mathrm{M} \mathrm{HNO}_{3}$

being below the ICP-MS detection limit. This fact indicates that $D_{\text {Eu }}$ is above 500 even at the lowest mixing time available for $\left[\mathrm{HNO}_{3}\right]=10 \mathrm{mM}$.

\subsection{Extraction kinetics of Eu from $4 \mathrm{M} \mathrm{HNO}_{3}$ for two different TODGA concentrations}

As can been seen in Fig. $5,\left[\mathrm{HNO}_{3}\right]=4 \mathrm{M}$ is a good compromise between easiness of sampling and time needed to reach equilibrium. Therefore, further kinetics experiments were performed at this acidity for two different TODGA concentrations with extended mixing time (up to $25 \mathrm{~h}$ ) to assure the equilibration of metal extraction. The results of this experiment are shown in Fig. 6.

\subsection{Discussion of the experimental results}

Data displayed in Fig. 1 show that the presence or absence of TODGA does not modify the water solubilization in the IL at $\left[\mathrm{HNO}_{3}\right]=1 \mathrm{M}$, which is consistent with the rather low TODGA concentration used in this work. At low acidity ( $1 \mathrm{M})$ about $0.95 \mathrm{M}(\sim 12000 \mathrm{ppm})$ of water is present in the equilibrated IL, while $2.72 \mathrm{M}(\sim 33000 \mathrm{ppm})$ is present in the highly acidic sample $(7 \mathrm{M})$. These results are in agreement with previous work. $^{23,24}$ Whatever the nitric acid concentration, the time needed to reach equilibrium of water extraction is very short. In particular, equilibrium is reached below $t=5 \mathrm{~min}$ for $4 \mathrm{M}$ $\mathrm{HNO}_{3}$.

Similarly, data plotted in Fig. 2 and 3 show that the low TODGA concentrations of this work do not affect the $\mathrm{H}^{+}$ solubilization in the IL phase. On average, $90 \%$ of the initial $\mathrm{H}^{+}$amount remains in the aqueous phase, a percentage in line with previous published data. ${ }^{22,24}$ It is important to note that for an initial nitric acid concentration equal to $4 \mathrm{M}$, the amount of $\mathrm{H}^{+}$transferred to the IL phase is in large excess as compared to the initial europium value in the aqueous phase.

Similarly, the results in Fig. 4 show that the equilibrium is reached within $10 \mathrm{~min}$ at maximum for the $\mathrm{C}_{1} \mathrm{C}_{4} \mathrm{im}^{+}$ solubilization. Additional experiments performed at $0.01 \mathrm{M}$ acid give $\mathrm{C}_{1} \mathrm{C}_{4} \mathrm{im}^{+}$concentration equal to $17 \mathrm{mM}$, in line with the value for pure water published by Shimijo et al. ${ }^{6}$ and Toh et $a .^{25}(16 \mathrm{mM})$ or Kakiuchi ${ }^{26}\left(17 \mathrm{mmol} \mathrm{kg}^{-1}\right)$. At $1 \mathrm{M} \mathrm{HNO}_{3}$ about $33 \mathrm{mM}$ of $\mathrm{C}_{1} \mathrm{C}_{4} \mathrm{im}^{+}$solubilized in the aqueous phase, whereas a concentration of $114 \mathrm{mM}$ was determined in the aqueous phase consisting of $7 \mathrm{M} \mathrm{HNO}_{3}$. These results indicate a strong dependency of the $\mathrm{C}_{1} \mathrm{C}_{4} \mathrm{im}^{+}$solubilization in the aqueous phase on the nitric acid concentration. This trend is in a good agreement with data published by Gaillard et al. ${ }^{24}$ despite the different acids used $\left(\mathrm{HClO}_{4}\right.$ and $\left.\mathrm{HCl}\right)$. No other references are known on that subject.

By contrast to the data obtained for $\mathrm{H}_{2} \mathrm{O}, \mathrm{H}^{+}$and $\mathrm{C}_{1} \mathrm{C}_{4} \mathrm{im}^{+}$ (Fig. 1 to 4 ), for which the equilibrium value is reached at very short times whatever the chemical conditions, the Eu kinetic profile displays rather complicated features (Fig. 5). Our data show that $D_{\mathrm{Eu}}$ equilibrium is reached rapidly only for the two limiting acidities of this work, namely 0.01 and $7 \mathrm{M} \mathrm{HNO}_{3}$. Below $\left[\mathrm{HNO}_{3}\right]=4 \mathrm{M}, D_{\mathrm{Eu}}$ values are high or very high but could not be determined precisely, either because the kinetics is very slow (i.e. $\left[\mathrm{HNO}_{3}\right]=1 \mathrm{M}$ and $2 \mathrm{M}$ ) or because the extraction process is very efficient and fast (i.e. $\left[\mathrm{HNO}_{3}\right]=10 \mathrm{mM}$ ).

Although comparison is somehow difficult, because the chemical conditions are different, our results differ markedly from what is known in several classical solvents in which the extraction kinetics of europium with [TODGA] $=50 \mathrm{mM}$, measured for $\left[\mathrm{HNO}_{3}\right]=1 \mathrm{M}$ (dodecane) or $\left[\mathrm{HNO}_{3}\right]=3 \mathrm{M}$ (chloroform, toluene, 1,2-dichloroethane) is relatively fast. Under these chemical conditions, having both phases in contact for $10 \mathrm{~min}$ is sufficient to attain the equilibration state $^{27}$ while for 1-octanol $\left(\left[\mathrm{HNO}_{3}\right]=3 \mathrm{M}\right)$ the metal extraction is slower, as $30 \mathrm{~min}$ is necessary to reach the extraction plateau. This was attributed, in part, to the high viscosity of 1-octanol $(\eta=8.93 \mathrm{cP})$ as compared to values in the range of $1.4 \mathrm{cP}$ (dodecane) to $0.55 \mathrm{cP}$ (toluene) for the other solvents. ${ }^{27}$ As the viscosity of $\left[\mathrm{C}_{1} \mathrm{C}_{4} \mathrm{im}\right]\left[\mathrm{Tf}_{2} \mathrm{~N}\right]$ is in the range of tenths of a $\mathrm{cP}^{28}$ even when water-saturated, the very fast kinetics observed for $\left[\mathrm{HNO}_{3}\right]=10 \mathrm{mM}$ demonstrates that viscosity is not the only parameter influencing the extraction kinetics in our case.

Comparison is easier with the work of Shimojo et al. ${ }^{6}$ These authors studied Eu (and other lanthanide ions) extraction from nitric aqueous phases toward $\left[\mathrm{C}_{1} \mathrm{C}_{n} \mathrm{im}\right]\left[\mathrm{Tf}_{2} \mathrm{~N}\right] \operatorname{ILs}(n=2,4$, 6 ), with the help of [TODGA] $=0.2 \mathrm{mM}$. No clear indication of a preliminary kinetic study can be found in this paper and the experimental procedure they used consisted of shaking on a vortex mixer for $15 \mathrm{~min}$, which was assumed to be enough for reaching equilibrium under all chemical conditions and, in particular, from $\left[\mathrm{HNO}_{3}\right]=1 \mathrm{mM}$ to $\left[\mathrm{HNO}_{3}\right]=1 \mathrm{M}$. Actually, this value of the mixing time is in perfect agreement with our data at $\left[\mathrm{HNO}_{3}\right]=10 \mathrm{mM}$, although the TODGA concentration is different in the two studies. Furthermore, obviously, the very high Ln(III) extraction ratios obtained by Shimojo et al. indicate that equilibrium is reached before $t=15 \mathrm{~min}$ below $\left[\mathrm{HNO}_{3}\right]=0.1 \mathrm{M}$. However, our data show that $15 \mathrm{~min}$ is not enough at higher nitric acid concentrations, which thus would explain why Shimojo et al. observed no significant extraction above $\left[\mathrm{HNO}_{3}\right]=1 \mathrm{M}$ using their protocol. In view of our results, the very low distribution ratios they obtained are thus not due to the inefficiency of the extraction process but to its slowness instead.

Long equilibration times, in the range of $3 \mathrm{~h}$, are also found for Am(III) extracted by TODGA in $\left[\mathrm{C}_{1} \mathrm{C}_{n} \mathrm{im}\right]\left[\mathrm{PF}_{6}\right](n=4,6,8)$ at 
$\left[\mathrm{HNO}_{3}\right]=3 \mathrm{M}^{7}$ and for $\mathrm{Am}(\mathrm{III})$ extraction at $\left[\mathrm{HNO}_{3}\right]=0.5 \mathrm{M}$ with $1 \mathrm{mM}$ of $T$-DGA, a tripodal diglycolamide in $\left[\mathrm{C}_{1} \mathrm{C}_{n} \mathrm{im}\right]\left[\mathrm{Tf}_{2} \mathrm{~N}\right](n$ $=4,6,8) \cdot{ }^{15}$ In this experiment, equilibrium was attained in the range $60 \mathrm{~min}(n=4)$ to $120 \mathrm{~min}(n=8)$ and this was ascribed to the high viscosities of the ILs used. As compared to our work, the ligand and/or the metal ion differ so again, comparison should be made with caution but these results show that slow kinetics are not rare in IL systems, with other indications to be found in Yoon et al. ${ }^{14}$ for Ce(III) extraction by some phosphoric acid derivatives in $\left[\mathrm{C}_{1} \mathrm{C}_{4} \mathrm{im}\right]\left[\mathrm{PF}_{6}\right]$, at $\left[\mathrm{HNO}_{3}\right]=0.1 \mathrm{M}$. Note also that long equilibration times are not restricted to $\mathrm{Ln}$ and $\mathrm{An}$ elements, as similar results are found for $\mathrm{Ni}(\mathrm{II}), \mathrm{Cu}(\mathrm{II})$ and $\mathrm{Pb}$ (II) extraction by a thiophenol ligand dissolved in $\left[\mathrm{C}_{1} \mathrm{C}_{4} \mathrm{im}\right]\left[\mathrm{PF}_{6}\right]^{29}$ or for $\mathrm{Rh}(\mathrm{III})$ extracted by CMPO. ${ }^{16}$ However, we would like to point out that kinetics are not always slow in ILs, as other works, dealing with $\mathrm{U}(\mathrm{VI})$ extraction by TBP, clearly indicate that less than $1 \mathrm{~min}$ is needed to reach equilibrium. $^{30}$ Other data show that $\mathrm{U}(\mathrm{VI})$ extraction using malonamides in $\left[\mathrm{C}_{1} \mathrm{C}_{4} \mathrm{im}\right]\left[\mathrm{Tf}_{2} \mathrm{~N}\right]$, at two different acidities requires less than $1 \mathrm{~h}$ to reach equilibrium. ${ }^{22}$

As a conclusion to this experimental part, we would like to insist on the need to check extraction kinetics of metal ions using ionic liquids, for several very different acidities of the aqueous phase, and in particular at "medium" acidities, in order to assess the reliability of the distribution ratios.

\section{Modelling the extraction kinetics}

\subsection{Chemical equations and mathematical treatment}

We now turn to a first attempt to describe, on a chemical and mathematical basis, our kinetic results as displayed in Fig. 6 $\left(\left[\mathrm{HNO}_{3}\right]=4 \mathrm{M},[\mathrm{TODGA}]=1 \mathrm{mM}\right.$ or $\left.2 \mathrm{mM}\right)$, hoping that the approach proposed here could be of some general application. Although the viscosity of the solvent certainly plays a role in the kinetics of ion transfer, we will not consider this point in detail and will focus on the chemical aspects only. As a matter of fact, at least part of the kinetics we observe is driven by chemical aspects, because the data we obtained at [TODGA] $=1$ $\mathrm{mM}$ differ from those at [TODGA] $=2 \mathrm{mM}$, which cannot be ascribed to changes in the viscosity of the IL phase, owing to the very low TODGA concentrations in these two experiments.

The metallic cation extraction mechanism in ILs has been investigated in detail in several publications and this point has been reviewed recently. ${ }^{31,32}$ All publications agree that the extraction mechanism in ILs is quite different from that in molecular solvents and proceeds through ion exchange. Cationic exchange is proposed to account for data at low acidities, involving either the cation of the $\mathrm{IL} \mathrm{or} \mathrm{H}^{+}$present in the IL phase (see Fig. 2 and 3) or a mixture of both species to counterbalance the charge of the metallic species. ${ }^{31}$ At high acidities, anionic exchange is proposed, involving exchange of either one $e^{9,30}$ or two anions ${ }^{33}$ of the IL to counterbalance the anionic metallic species. The turnover acidic concentration at which the anionic exchange becomes dominant as compared to the cationic exchange has been shown to depend strongly on the nature of the IL. ${ }^{10}$ As a matter of fact, our data do not allow the determination of whether a cationic or anionic exchange (or a mixture of both) takes place at $\left[\mathrm{HNO}_{3}\right]=4 \mathrm{M}$ and the exact determination of the mechanism is out of the scope of this study. Nevertheless, our data are liable to some chemical and mathematical modelling concerning the kinetic aspects, as described in the following.

Let's first assume that the extraction proceeds through cationic exchange. The most general chemical expression is: ${ }^{34}$

$$
\begin{aligned}
& \mathrm{Eu}^{3+}+i \mathrm{NO}_{3}^{-}+k \overline{\mathrm{C}_{1} \mathrm{C}_{4} \mathrm{im}^{+}}+l \overline{\mathrm{H}^{+}}+ \\
& p \overline{\mathrm{TODGA}} \underset{k_{2}}{\stackrel{k_{1}}{\rightleftarrows}} \overline{\left(\mathrm{Eu}\left(\mathrm{NO}_{3}\right)_{i} \mathrm{TODGA}_{p}\right)^{(3-i)+}}+k \mathrm{C}_{1} \mathrm{C}_{4} \mathrm{im}^{+}+l \mathrm{H}^{+}
\end{aligned}
$$

Where $i<3$ and $(k+l)=(m-i)$ and where $k_{1}$ and $k_{2}$ are the kinetic constants. Bars over the species indicate that they are dissolved in the IL phase.

Assuming $i=0$ and $l=0$ in eqn (2) above leads to the chemical equation proposed by Shimojo et $a l .{ }^{6}$ in their work devoted to $\operatorname{Ln}(\mathrm{III})$ extraction by TODGA in $\mathrm{C}_{1} \mathrm{C}_{n} \operatorname{imTf}_{2} \mathrm{~N}(n=4,6$, $8)$, where they considered one metal ion extracted into the ionic liquid by three molecules of TODGA with exchange of three cationic constituents of the ionic liquid.

The mathematical system derived from eqn (2) is:

$$
\begin{aligned}
& \frac{\mathrm{d}\left[\mathrm{Eu}^{3+}\right]}{\mathrm{d} t}=-k_{1}\left[\mathrm{Eu}^{3+}\right]\left[\mathrm{NO}_{3}^{-}\right]^{i}\left[\overline{\mathrm{C}_{1} \mathrm{C}_{4} \mathrm{im}^{+}}\right]^{k}\left[\overline{\mathrm{H}^{+}}\right]^{l}[\overline{\mathrm{TODGA}}]^{p}+ \\
& k_{2}[\overline{\mathrm{X}}]\left[\mathrm{C}_{1} \mathrm{C}_{4} \mathrm{im}^{+}\right]^{k}\left[\mathrm{H}^{+}\right]^{l}
\end{aligned}
$$

$\frac{\mathrm{d}[\overline{\mathrm{X}}]}{\mathrm{d} t}=+k_{1}\left[\mathrm{Eu}^{3+}\right]\left[\mathrm{NO}_{3}^{-}\right]^{i}\left[\overline{\mathrm{C}_{1} \mathrm{C}_{4} \mathrm{im}^{+}}\right]^{k}\left[\overline{\mathrm{H}^{+}}\right]^{l}\left[\overline{\mathrm{TODGA}^{p}}\right]^{p}$

$k_{2}[\overline{\mathrm{X}}]\left[\mathrm{C}_{1} \mathrm{C}_{4} \mathrm{im}^{+}\right]^{k}\left[\mathrm{H}^{+}\right]^{l}$

where $\mathrm{X}$ is the europium complex in the IL phase.

For the fixed condition of $\left[\mathrm{HNO}_{3}\right]=4 \mathrm{M}$, and considering the low europium concentration of this work, it is safe to consider that the nitrate, IL cation and $\mathrm{H}^{+}$concentrations in the aqueous phase, together with the $\mathrm{IL}$ cation and $\mathrm{H}^{+}$concentrations in the IL phase are constant as a function of time (see section 3). Therefore all these terms can be included in a conditional constant. The TODGA concentration is also a constant for a given experiment but, as we performed one series with [TODGA] $=1 \mathrm{mM}$ and another one with [TODGA] = $2 \mathrm{mM}$, we keep this factor separated from the conditional constant. The system can thus be written as:

$$
\begin{gathered}
\frac{\mathrm{d}\left[\mathrm{Eu}^{3+}\right]}{\mathrm{d} t}=-k_{1}{ }^{\prime}\left[\mathrm{Eu}^{3+}\right][\overline{T O D G A}]^{p}+k_{2}{ }^{\prime}[\overline{\mathrm{X}}] \\
\frac{\mathrm{d}[\mathrm{X}]}{\mathrm{d} t}=+k_{1}{ }^{\prime}\left[\mathrm{Eu}^{3+}\right][\overline{\text { TODGA }}]^{p}-k_{2}{ }^{\prime}[\overline{\mathrm{X}}]
\end{gathered}
$$

Where $k_{1}{ }^{\prime}$ and $k_{2}{ }^{\prime}$ are conditional kinetic constants.

Let us now consider the anionic exchange hypothesis. The most general chemical expression is: 


$$
\begin{aligned}
& \mathrm{Eu}^{3+}+(3+i) \mathrm{NO}_{3}^{-}+i \overline{\mathrm{Tf}_{2} \mathrm{~N}^{-}}+ \\
& p \overline{\mathrm{TODGA}^{+}} \underset{k_{2}}{\stackrel{k_{1}}{\rightleftarrows}} \overline{\left(\mathrm{Eu}\left(\mathrm{NO}_{3}\right)_{(3+i)} \mathrm{TODGA}_{p}\right)^{i-}}+i \mathrm{Tf}_{2} \mathrm{~N}^{-}
\end{aligned}
$$

Which leads to the following mathematical system:

$$
\begin{gathered}
\frac{\mathrm{d}\left[\mathrm{Eu}^{3+}\right]}{\mathrm{d} t}=-k_{1}\left[\mathrm{Eu}^{3+}\right]\left[\mathrm{NO}_{3}{ }^{-}\right]^{(i+3)}[\overline{\mathrm{TODGA}}]^{p}+k_{2}[\overline{\mathrm{X}}]\left[\mathrm{Tf}_{2} \mathrm{~N}^{-}\right]^{i}(8) \\
\frac{\mathrm{d}[\overline{\mathrm{X}}]}{\mathrm{d} t}=k_{1}\left[\mathrm{Eu}^{3+}\right]\left[\mathrm{NO}_{3}{ }^{-}\right]^{(i+3)}[\overline{\mathrm{TODGA}}]^{p}-k_{2}[\overline{\mathrm{X}}]\left[\mathrm{Tf}_{2} \mathrm{~N}^{-}\right]^{i}
\end{gathered}
$$

Owing to the constant values of the nitrate and TODGA concentrations and assuming a constant $\mathrm{Tf}_{2} \mathrm{~N}^{-}$concentration, in line with the behavior of its counter cation $\mathrm{C}_{1} \mathrm{C}_{4} \mathrm{im}^{+}$(Fig. 4), this system is formally identical to that derived above for the cationic exchange hypothesis and leads to the unified mathematical system of eqn (5) and (6), which we will consider in the rest of this work.

Since nitrate ions complex europium in water, two complexation equilibria are also included in the model:

$$
\begin{gathered}
\mathrm{Eu}^{3+}+\mathrm{NO}_{3}{ }^{-} \stackrel{K_{3}}{\longleftarrow} \mathrm{EuNO}_{3}{ }^{2+} \\
\mathrm{EuNO}_{3}{ }^{2+}+\mathrm{NO}_{3}{ }^{-} \stackrel{K_{4}}{\longleftarrow} \mathrm{Eu}\left(\mathrm{NO}_{3}\right)_{2}{ }^{+}
\end{gathered}
$$

Where $K_{3}$ and $K_{4}$ are the conditional equilibrium constants at $\left[\mathrm{HNO}_{3}\right]=4 \mathrm{M}$.

Let us now turn to a mathematical approach to this chemical system. Eqn (2) (or eqn (7)), which describes an extraction process, is supposed to be the superposition of two (possibly slow) kinetic equations, with the corresponding $k_{1}{ }^{\prime}$ and $k_{2}{ }^{\prime}$ reaction rate constants. By contrast, we assume the other two chemical equilibria (eqn (10) and (11), with the corresponding $K_{3}$ and $K_{4}$ equilibrium constants) to be very fast as compared to the extraction and back transfer processes. Therefore, the Eu concentration in the aqueous phase is constantly decreasing due to its extraction into the IL phase and, as a consequence, the speciation of the remaining Eu in the aqueous phase is also time dependent. Mathematically speaking, the chemical system above is a mixture of differential equations and of non-linear relationships. This is not an unusual situation, as the same type of mathematical systems is encountered in the case of excited state dynamics coupled with complexation in the ground state. ${ }^{35}$

Solving eqn (5) and (6) we obtain:

$$
\begin{gathered}
{\left[\mathrm{Eu}^{3+}\right]=A \exp \left[-\left(k_{1}{ }^{\prime}[\overline{\text { TODGA }}]^{p}-k_{2}{ }^{\prime}\right) t\right]+B} \\
{[\overline{\mathrm{X}}]=C \exp \left[-\left(k_{1}{ }^{\prime}[\overline{\mathrm{TODGA}}]^{p}+k_{2}{ }^{\prime}\right) t\right]+D}
\end{gathered}
$$

Where $A, B, C$ and $D$ are constant values depending on the boundary conditions.

At any time, the following equations apply:

$$
\begin{gathered}
{\left[\mathrm{Eu}^{3+}\right]+\left[\mathrm{Eu}\left(\mathrm{NO}_{3}\right)^{2+}\right]+\left[\mathrm{Eu}\left(\mathrm{NO}_{3}\right)_{2}{ }^{+}\right]+[\overline{\mathrm{X}}]=[\mathrm{Eu}]_{\text {init }}} \\
K_{3}=\frac{\left[\mathrm{Eu}\left(\mathrm{NO}_{3}\right)^{2+}\right]}{\left[\mathrm{Eu}^{3+}\right]\left[\mathrm{NO}_{3}{ }^{-}\right]} \\
K_{4}=\frac{\left[\mathrm{Eu}\left(\mathrm{NO}_{3}\right)_{2}^{+}\right]}{\left[\mathrm{Eu}\left(\mathrm{NO}_{3}\right)^{2+}\right]\left[\mathrm{NO}_{3}{ }^{-}\right]}
\end{gathered}
$$

Where $[\mathrm{Eu}]_{\text {init }}$ is the initial europium concentration introduced in the aqueous phase at time zero.

The expression of $A, B, C$ and $D$ and, thereafter, the expressions for $\left[\mathrm{Eu}\left(\mathrm{NO}_{3}\right)^{2+}\right]$ and $\left[\mathrm{Eu}\left(\mathrm{NO}_{3}\right)_{2}{ }^{+}\right]$can be easily calculated from eqn (15) and (16) and the boundary conditions:

At $t=0$ :

$$
[\overline{\mathrm{X}}]=C+D=0
$$

$$
\begin{gathered}
{\left[\mathrm{Eu}^{3+}\right]+\left[\mathrm{Eu}\left(\mathrm{NO}_{3}\right)^{2+}\right]+\left[\mathrm{Eu}\left(\mathrm{NO}_{3}\right)_{2}{ }^{+}\right]=\mathrm{Eu}_{\text {init }}=} \\
(A+B)\left(1+K_{3}\left[\mathrm{NO}_{3}{ }^{-}\right]+K_{3} K_{4}\left[\mathrm{NO}_{3}{ }^{-}\right]^{2}\right)
\end{gathered}
$$

At $t=+\infty$

$$
\frac{[\overline{\mathrm{X}}]}{\left[\mathrm{Eu}^{3+}\right]}=\frac{k_{1}^{\prime}\left[\overline{\mathrm{TODGA}^{p}}{ }^{p}\right.}{k_{2}^{\prime}}=\frac{D}{B}
$$

$$
\begin{aligned}
& {\left[\mathrm{Eu}^{3+}\right]+\left[\mathrm{Eu}\left(\mathrm{NO}_{3}\right)^{2+}\right]+\left[\mathrm{Eu}\left(\mathrm{NO}_{3}\right)_{2}^{+}\right]+[\overline{\mathrm{X}}]} \\
& =\mathrm{Eu}_{\text {init }}=B\left(1+K_{3}\left[\mathrm{NO}_{3}^{-}\right]+K_{3} K_{4}\left[\mathrm{NO}_{3}^{-}\right]^{2}+k_{1}^{\prime} / k_{2}^{\prime}\right)
\end{aligned}
$$

Finally, the data to be fitted (see Fig. 6) correspond to the total europium concentration in the aqueous phase, $[\mathrm{Eu}]_{\text {tot, }}$, thus including the contributions of $\left[\mathrm{Eu}\left(\mathrm{NO}_{3}\right)^{2+}\right]$ and $\left[\mathrm{Eu}\left(\mathrm{NO}_{3}\right)_{2}^{+}\right]$, as:

$$
\begin{aligned}
& {[\mathrm{Eu}]_{\mathrm{tot}}=\left(A \exp \left(-\left(k_{1}^{\prime}[\overline{T O D G A}]^{p}+k_{2}^{\prime}\right) t\right]+B\right) \times} \\
& \left(1+K_{3}\left[\mathrm{NO}_{3}^{-}\right]+K_{3} K_{4}\left[\mathrm{NO}_{3}^{-}\right]^{2}\right) \\
& A=\frac{[\mathrm{Eu}]_{\text {init }}}{1+K_{3}\left[\mathrm{NO}_{3}^{-}\right]+K_{3} K_{4}\left[\mathrm{NO}_{3}^{-}\right]^{2}}- \\
& \frac{[\mathrm{Eu}]_{\text {init }}}{1+K_{3}\left[\mathrm{NO}_{3}^{-}\right]+K_{3} K_{4}\left[\mathrm{NO}_{3}^{-}\right]^{2}+k_{1}^{\prime} / k_{2}^{\prime}} \\
& B=\frac{[\mathrm{Eu}]_{\text {init }}}{1+K_{3}\left[\mathrm{NO}_{3}^{-}\right]+K_{3} K_{4}\left[\mathrm{NO}_{3}^{-}\right]^{2}+k_{1}^{\prime} / k_{2}^{\prime}}
\end{aligned}
$$

\subsection{Data fitting}

In eqn (21), the only unknown parameters are $k_{1}{ }^{\prime}, k_{2}{ }^{\prime}$ and $p$. We fixed $K_{3}=1.86$ and $K_{4}=0.23$ based on a publication in 
Table 1 The parameters used in the fitting of the experimental results to the model

\begin{tabular}{llll}
\hline Strategy & $k_{1}{ }^{\prime}\left(\mathrm{mM}^{-1.25} \mathrm{~min}^{-1}\right)$ & $k_{2}{ }^{\prime}\left(\mathrm{min}^{-1}\right)$ & $p$ \\
\hline $1 \mathrm{mM}$ alone & $1.2 \times 10^{-2}\left( \pm 0.1 \times 10^{-2}\right)$ & $5 \times 10^{-5}\left( \pm 1 \times 10^{-5}\right)$ & $\chi^{2}$ \\
$2 \mathrm{mM}$ alone & $1.3 \times 10^{-2}\left( \pm 0.1 \times 10^{-2}\right)$ & $4 \times 10^{-5}\left( \pm 1 \times 10^{-5}\right)$ & $1^{a}$ \\
$1 \mathrm{mM}$ and 2 mM together & $1.1 \times 10^{-2}\left( \pm 0.1 \times 10^{-2}\right)$ & $5 \times 10^{-5}\left( \pm 2 \times 10^{-5}\right)$ & $1.3( \pm 0.2)$ \\
${ }^{a}$ fixed value. & & & \\
\end{tabular}

which the two successive nitrate/europium complexation constants have been determined at a total ionic strength of 5 M. ${ }^{36}$ This ionic strength value slightly differs from our own chemical conditions but the other literature values collected by the authors show that in the range $c a .2-5 \mathrm{M}$ the equilibrium constants do not change much. The partial dissociation of the nitric acid in the aqueous phase at $\left[\mathrm{HNO}_{3}\right]=4 \mathrm{M}$ was taken into account, based on the results obtained by Ruas et al. ${ }^{37}$

The experimental values corresponding to the two TODGA concentrations were fitted following different strategies for which the relevant parameters are listed in Table 1 . The $\chi^{2}$ values are also displayed and the uncertainties on the parameters are calculated for a change of $5 \%$ of the $\chi^{2}$ values. The results are shown in Fig. 7 as solid lines. We deliberately used a log-log scale in Fig. 7 to highlight the trends at short and long mixing times and for this $\log -\log$ plot, we artificially set the experimental $\left[\mathrm{Eu}^{3+}\right]_{\text {tot }}$ value at time $t=1 \mathrm{~min}$ for graphical facility.

\section{Discussion}

We first fitted the two series at [TODGA] $=1 \mathrm{mM}$ and $2 \mathrm{mM}$ independently, fixing $p=1$ in eqn (21) in each case (see Table 1 and Fig. 7). Despite the assumptions made for the calculations, the fit is in very good agreement with the data for [TODGA $]=1 \mathrm{mM}$, while the plateau value is not perfectly recovered for $[$ TODGA] $=2 \mathrm{mM}$. Although the additional contact time (see section 2.2) was not taken into account, the

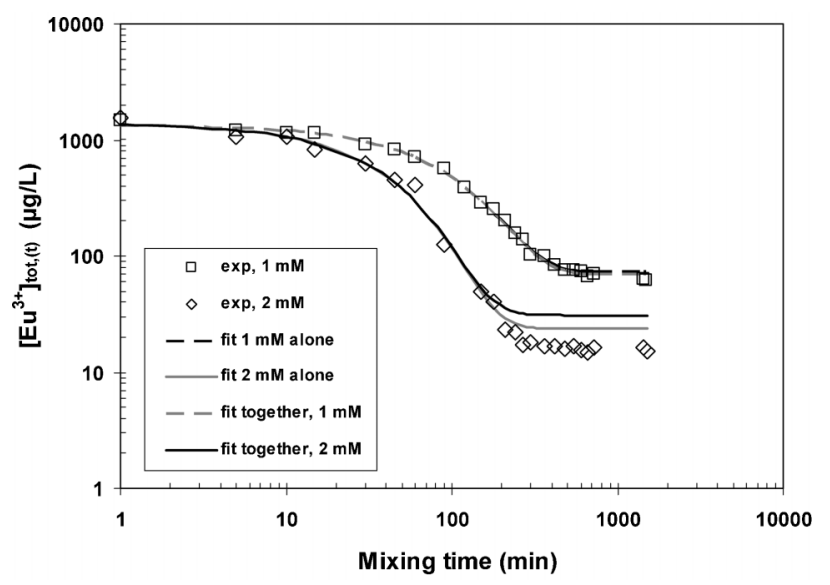

Fig. 7 Fitting of the experimental results to the model as a function of mixing time. Org. phase: $1 \mathrm{mM}$ TODGA (open squares) or $2 \mathrm{mM}$ (open diamonds) in $\left[\mathrm{C}_{1} \mathrm{C}_{4} \mathrm{im}\right]\left[\mathrm{Tf}_{2} \mathrm{~N}\right]$. Aq. phase: $10 \mu \mathrm{M} \mathrm{Eu}\left(\mathrm{NO}_{3}\right)_{3}, 4 \mathrm{M} \mathrm{HNO}_{3}$. agreement between calculated and experimental $\left[\mathrm{Eu}^{3+}\right]_{\text {tot }}$ values at short time is very good for the two series. The fact that the two $k_{1}{ }^{\prime}$ values are identical (within uncertainties) is a strong indication that $p$ is actually close to 1 . The two $k_{2}{ }^{\prime}$ values are identical, within uncertainties, which is in support of our model. We also performed a fit of the two series together, letting $p$ be a free parameter (see Table 1 and Fig. 7). As deduced from the examination of the previous fits, a value close to 1 is found for $p$. The fit is not able to perfectly recover the experimental values at long mixing times for [TODGA] $=2$ $\mathrm{mM}$, as could be inferred from the two independent fits. Although the quality of the fit is rather satisfying as a whole, we think one cannot safely rely on the fitted value of $p=1.3 \pm$ 0.2 . In order to get a reliable fitted value, several additional experiments would be needed, involving a much larger range of TODGA concentrations. As a matter of fact, a value of $c a$. one TODGA per $\mathrm{Eu}^{3+}$ ion appears somewhat low as compared to literature data in molecular solvents. The number of TODGA molecules involved in the extraction reaction in classical solvents depends on the polarity of the solvent. Extracted species with poor lipophilicity containing just two molecules of TODGA can be stable in polar diluents (1-octanol and 1,2dichloroethane), whereas the highly lipophilic ones require 3 or 4 TODGA molecules to remain stable in non-polar diluents (e.g. chloroform, toluene and 1-dodecane). ${ }^{38}$ It is nevertheless risky to base a discussion devoted to TODGA stoichiometry in ILs on such an empirical rule, because defining a polarity scale in ILs is rather difficult if not meaningless (see for instance the conclusion in ref. 39), and so is the estimation of a dielectric constant in such conducting media. However, some methods indicate that the dielectric constant of $\left[\mathrm{C}_{1} \mathrm{C}_{2} \mathrm{im}\right]\left[\mathrm{Tf}_{2} \mathrm{~N}\right]$ is rather low, in the range of $15,{ }^{40}$ which would be somewhat in line with a low TODGA stoichiometry. There is not much data available on metal extraction with TODGA in ILs. Turanov et $a l^{41}$ reported a stoichiometry equal to $1: 3$ for the metal (Ca, $\mathrm{Sr}$ and $\mathrm{Ba}$ )-TODGA complex in $\left[\mathrm{C}_{1} \mathrm{C}_{4} \mathrm{im}\right]\left[\mathrm{Tf}_{2} \mathrm{~N}\right]$ and Shimojo et al. ${ }^{6}$ found the same stoichiometry for $\mathrm{La}, \mathrm{Eu}$ and $\mathrm{Lu}$ extraction into TODGA/[ $\left.\mathrm{C}_{1} \mathrm{C}_{2} \mathrm{im}\right]\left[\mathrm{Tf}_{2} \mathrm{~N}\right]$ but another recent work evidences a 1:2 stoichiometry for Am : TODGA in various $\left[\mathrm{C}_{1} \mathrm{C}_{n} \mathrm{im}\right]\left[\mathrm{PF}_{6}\right]$ ILs. $^{7}$ Actually, one TODGA per Eu unit is not impossible per se: the europium solvation sphere could be completed by $\mathrm{NO}_{3}{ }^{-}$and/or $\mathrm{H}_{2} \mathrm{O}$ moieties that are present in large amounts in the IL phase. Furthermore, a low TODGA stoichiometry in the extracted species would be one explanation to the very high extraction distribution ratio observed as compared to molecular solvents. Finally, there is one possible experimental artefact in the determination of the TODGA 
stoichiometry through the classical slope analysis method. In the case of insufficient time to reach equilibrium, the measured distribution ratio would be largely underestimated at low TODGA concentrations while it would be better estimated at the highest TODGA concentrations, because increasing TODGA concentration speeds up the kinetics. In this way, an overestimated TODGA stoichiometry would be obtained. This remark most probably applies to the work of Shimojo $^{6}$ (TODGA stoichiometry: 3 ), as explained above, may apply to the work of Turanov ${ }^{41}$ (TODGA stoichiometry: 3 ), while the $1: 2$ metal-TODGA stoichiometry obtained in the work of Sengupta ${ }^{7}$ has been obtained under safe kinetic conditions (TODGA stoichiometry: 2). Clearly, additional data are needed to solve this question.

Furthermore, our results, combined with those of Shimojo and co-workers, ${ }^{6}$ show that the europium extraction kinetics is very fast from aqueous solutions of low acidity $\left(10^{-2} \mathrm{M}\right.$ in this work and from $10^{-3} \mathrm{M}$ to $10^{-1} \mathrm{M}$ in Shimojo's publication), then slow in the medium acidity range (from $c a .1 \mathrm{M}$ to $4 \mathrm{M}$, this work) then somewhat fast again at very high acidity $(7 \mathrm{M}$, this work). This is an indication that metal extraction by TODGA in IL possibly involves more than just one extraction mechanism, all of them being liable to chemical effects, as already pinpointed in section 4.1. This would explain the relatively fast extraction kinetics at low and high nitric acid concentrations. This is in contrast to classical solvents where just one solvation mechanism describes Ln(III) extraction by TODGA. ${ }^{17,27}$ Actually, multiple extraction mechanisms in IL are not a new phenomenon and have been already reported and studied in details. ${ }^{9,10}$ Our first investigation into the question of kinetics shows that, under some assumptions, kinetics studies may also bring some insights into the understanding of the extraction mechanism.

\section{Conclusion}

The experimental data of this work evidence a strong influence on the kinetics of europium extraction in one given ionic liquid of the ligand and acid concentrations, thus demonstrating that beside the physical phenomenon related to viscosity of the IL phase, a chemical phenomenon is involved in the kinetics regulation. A simple chemical model has been proposed and fitted to the data. In order to refine this model, additional experiments are required, possibly involving a larger range of chemical conditions.

On a more general aspect, questions that are currently under study in our laboratory deal with comparison of $\mathrm{Am} / \mathrm{Eu}$ kinetics in the TODGA/ $\mathrm{C}_{1} \mathrm{C}_{n} \mathrm{imTf}_{2} \mathrm{~N}$ system, because previous limited experiments already showed that in some cases, strong differences are to be found between the reactivity and the kinetics of $\mathrm{Am}, \mathrm{Eu}$ and $\mathrm{Cm}$ in IL solvents. ${ }^{42,43}$ This may also help to understand why some extraction systems in ILs display slow kinetics, while others are very fast.

\section{Acknowledgements}

The authors are indebted to Dr Andreas Wilden for the synthesis of TODGA.

\section{References}

1 X. Han and D. W. Armstrong, Acc. Chem. Res., 2007, 40, 1079-1086.

2 P. Sun and D. W. Armstrong, Anal. Chim. Acta, 2010, 661, 1-16.

3 M. Koel, Crit. Rev. Anal. Chem., 2005, 35, 177-192.

4 M. Freemantle, T. Welton and R. D. Rogers, An Introduction to Ionic Liquids, Royal Society of Chemistry, 2009.

5 I. A. Shkrob, S. D. Chemerisov and J. F. Wishart, J. Phys. Chem. B, 2007, 111, 11786-11793.

6 K. Shimojo, K. Kurahashi and H. Naganawa, Dalton Trans., 2008, 5083-5088.

7 A. Sengupta, P. K. Mohapatra, M. Iqbal, J. Huskens and W. Verboom, Dalton Trans., 2012, 41, 6970-6979.

8 S. Dai, Y. H. Ju and C. E. Barnes, J. Chem. Soc., Dalton Trans., 1999, 1201-1202.

9 I. Billard, A. Ouadi, E. Jobin, J. Champion, C. Gaillard and S. Georg, Solvent Extr. Ion Exch., 2011, 29, 577-601.

10 M. L. Dietz and D. C. Stepinski, Talanta, 2008, 75, 598-603.

11 M. L. Dietz and D. C. Stepinski, Green Chem., 2005, 7, 747-750.

12 P. Giridhar, K. A. Venkatesan, T. G. Srinivasan and P. R. V. Rao, J. Nucl. Radiochem. Sci., 2004, 5, 17-20.

13 A. W. Taylor, P. Licence and A. P. Abbott, Phys. Chem. Chem. Phys., 2011, 13, 10147-10154.

14 S. J. Yoon, J. G. Lee, H. Tajima, A. Yamasaki, F. Kiyono, T. Nakazato and H. Tao, J. Ind. Eng. Chem., 2010, 16, 350-354.

15 A. Sengupta, P. K. Mohapatra, M. Iqbal, W. Verboom, J. Huskens and S. V. Godbole, RSC Adv., 2012, 2, 7492-7500.

16 T. J. Bell and Y. Ikeda, Dalton Trans., 2012, 41, 4303-4305.

17 Y. Sasaki, Y. Sugo, S. Suzuki and S. Tachimori, Solvent Extr. Ion Exch., 2001, 19, 91-103.

18 X. Hérès, C. Sorel, M. Miguirditchian, B. Camès, C. Hill, I. Bisel, D. Espinoux, C. Eysseric, P. Baron and B. Lorrain, GLOBAL, Paris, France, 2009.

19 I. Billard and S. Georg, Helv. Chim. Acta, 2009, 92, 2227-2237.

20 Y. Sasaki and R. Choppin, Anal. Sci., 1996, 12, 225-230.

21 G. Modolo, H. Asp, C. Schreinemachers and H. Vijgen, Solvent Extr. Ion Exch., 2007, 25, 703-721.

22 M. Bonnaffe-Moity, A. Ouadi, V. Mazan, S. Miroshnichenko, D. Ternova, S. Georg, M. Sypula, C. Gaillard and I. Billard, Dalton Trans., 2012, 41, 7526-7536.

23 J. McFarlane, W. B. Ridenour, H. Luo, R. D. Hunt, D. W. DePaoli and R. X. Ren, Sep. Sci. Technol., 2005, 40, 1245-1265.

24 C. Gaillard, V. Mazan, S. Georg, O. Klimchuk, M. Sypula, I. Billard, R. Schurhammer and G. Wipff, Phys. Chem. Chem. Phys., 2012, 14, 5187-5199.

25 S. L. I. Toh, J. McFarlane, C. Tsouris, D. W. DePaoli, H. Luo and S. Dai, Solvent Extr. Ion Exch., 2006, 24, 33-56.

26 T. Kakiuchi, Anal. Sci., 2008, 24, 1221-1230. 
27 Y. Sasaki, P. Rapold, M. Arisaka, M. Hirata, T. Kimura, C. Hill and G. Cote, Solvent Extr. Ion Exch., 2007, 25, 187-204.

28 H. Tokuda, S. Tsuzuki, M. A. B. H. Susan, K. Hayamizu and M. Watanabe, J. Phys. Chem. B, 2006, 110, 19593-19600.

29 R. Lertlapwasin, N. Bhawawet, A. Imyim and S. Fuangswasdi, Sep. Purif. Technol., 2010, 72, 70-76.

30 T. J. Bell and Y. Ikeda, Dalton Trans., 2011, 40, 10125-10130.

31 I. Billard, in Handbook on the Physics and Chemistry of Rare Earths, ed. G. B. Jean-Claude and K. P. Vitalij, Elsevier, 2013, vol. 43, pp. 213-273.

32 I. Billard, A. Ouadi and C. Gaillard, Anal. Bioanal. Chem., 2011, 400, 1555-1566.

33 A. Rout, K. A. Venkatesan, T. G. Srinivasan and P. R. Vasudeva Rao, Radiochim. Acta, 2010, 98, 459-466.

34 I. Billard, A. Ouadi and C. Gaillard, Dalton Trans., 2013, 42, 6203.

35 I. Billard and K. Lützenkirchen, Radiochim. Acta, 2003, 91, 285-294.
36 S. Andersson, K. Eberhardt, C. Ekberg, J.-O. Liljenzin, M. Nilsson and G. Skarnemark, Radiochim. Acta, 2006, 94, 469-474.

37 A. Ruas, P. Pochon, J.-P. Simonin and P. Moisy, Dalton Trans., 2010, 39, 10148-10153.

38 S. A. Ansari, P. N. Pathak, M. Husain, A. K. Prasad, V. S. Parmar and V. K. Manchanda, Radiochim. Acta, 2006, 94, 307-312.

39 M. A. Ab Rani, A. Brant, L. Crowhurst, A. Dolan, M. Lui, N. H. Hassan, J. P. Hallett, P. A. Hunt, H. Niedermeyer, J. M. Perez-Arlandis, M. Schrems, T. Welton and R. Wilding, Phys. Chem. Chem. Phys., 2011, 13, 16831-16840.

40 T. Köddermann, C. Wertz, A. Heintz and R. Ludwig, Angew. Chem., Int. Ed., 2006, 45, 3697-3702.

41 A. N. Turanov, V. K. Karandashev and V. E. Baulin, Solvent Extr. Ion Exch., 2010, 28, 367-387.

42 S. Stumpf, I. Billard, P. J. Panak and S. Mekki, Dalton Trans., 2007, 240-248.

43 S. Stumpf, I. Billard, C. Gaillard, P. J. Panak and K. Dardenne, Inorg. Chem., 2008, 47, 4618-4626. 